\title{
Comparison of the Japanese Orthopaedic Association Score and the Japanese Orthopaedic Association Cervical Myelopathy Evaluation Questionnaire Scores: Time-Dependent Changes in Patients with Cervical Spondylotic Myelopathy and Posterior Longitudinal Ligament
}

\author{
Kazuya Oshima ${ }^{1,2}$, Motoki Iwasaki ${ }^{1}$, Hironobu Sakaura ${ }^{1}$, Takahito Fujimori ${ }^{1}$, \\ Yukitaka Nagamoto ${ }^{1}$, Hideki Yoshikawa ${ }^{1}$ \\ ${ }^{1}$ Department of Orthopaedic Surgery, Graduate School of Medicine, Osaka University, Osaka, Japan \\ ${ }^{2}$ Department of Orthopaedic Surgery, Osaka Medical Center for Cancer and Cardiovascular Diseases, Osaka, Japan
}

\section{Study Design: Prospective cohort study.}

Purpose: To identify differences in time-dependent perioperative changes between the Japanese Orthopaedic Association (JOA) score and the JOA Cervical Myelopathy Evaluation Questionnaire (JOACMEQ) score in patients with cervical spondylotic myelopathy (CSM) and posterior longitudinal ligament (OPLL) who underwent cervical laminoplasty.

Overview of Literature: The JOA score does not take into consideration patient satisfaction or quality of life. Accordingly, the JOACME 0 was designed in 2007 as a patient-centered assessment tool.

Methods: We studied 21 patients who underwent cervical laminoplasty. We objectively evaluated the time-dependent changes in JOACMEO scores and JOA scores for all patients before surgery and at 2 weeks, 3 months, 6 months, and 1 year after surgery.

Results: The average total JOA score and the recovery rate improved significantly after surgery in both groups, with a slightly better recovery rate in the OPLL group. Cervical spine function improved significantly in the CSM group but not in the OPLL group. Upper- and lower-extremity functions were more stable in the CSM group than in the OPLL group. The effectiveness rate of the JOACMEO for measuring quality of life was quite low in both groups. In both groups, the Spearman contingency coefficients were dispersed widely except for upper- and lower-extremity function.

Conclusions: Scores for upper- and lower-extremity function on the JOACMEQ correlated well with JOA scores. Because the JOACMEQ can also assess cervical spine function and quality of life, factors that cannot be assessed by the JOA score alone, the JOACMEQ is a more comprehensive evaluation tool.

Keywords: Questionnaires; Spinal cord diseases; Spondylosis; Ossification of posterior longitudinal ligament; Quality of life 


\section{Introduction}

In 1999 the Japanese Orthopaedic Association (JOA) instituted a committee to establish a new standard of assessment that was based on patient-centered methods. The Japanese Society for Spine Surgery and Related Research and the Japanese Society of Lumbar Spine Disorders revised the criteria for cervical spinal myelopathy and lumbar spinal disorder, producing the JOA Cervical Myelopathy Evaluation Questionnaire (JOACMEQ) and the JOA Back Pain Evaluation Questionnaire in 2007 [1-4]. We conducted a study to identify differences in postoperative time-dependent changes between the JOACMEQ and the JOA scores in patients with cervical spondylotic myelopathy (CSM) and in those with ossification of the posterior longitudinal ligament (OPLL) who underwent cervical laminoplasty.

\section{Materials and Methods}

This study was designed as prospective cohort study. Twenty-one patients enrolled in our study fulfilled the following criteria for inclusion: a clear history of progressive neurological deficiency due to cervical myelopathy, comparable radiography, magnetic resonance imaging, computed tomography findings verifying cervical stenosis at two or more levels, and acceptable cervical spine alignment without kyphotic deformity or radiological signs of instability. Patients with a history of cervical spine surgery or traumatic cervical lesions were excluded. Thirteen included subjects had CSM (the CSM group), and the other 8 had OPLL (the OPLL group). There were 9 males and 4 females in the CSM group, while all patients in the OPLL group were males. The average age at surgery was 65.2 years (range, 45-83 years) in the CSM group and 62.5 years (range, $46-70$ years) in the OPLL group. All patients underwent a unilateral expansive open-door laminoplasty augmented with hydroxyapatite spacers. The decompression patterns in the CSM group were C3-C6 in 12 patients and $\mathrm{C} 5-\mathrm{Th} 2$ in 1 patient; on the other hand those in the OPLL group were C3-C6 in 3 patients, $\mathrm{C} 3-\mathrm{C} 7$ in 3 patients and $\mathrm{C} 2-\mathrm{C} 6$ in 2 patients. No restenosis due to hinge closure or major surgery-related complications were observed during at least 1 year of follow-up. We objectively evaluated the time-dependent changes in the patients' JOACMEQ and JOA scores before surgery and at 2 weeks, 3 months, 6 months, and 1 year after cervical lamino- plasty. JOACMEQ is a patient-based evaluation method for a cervical myelopathy comprising 24 questions. The answers are evaluated according to the calculation offered from five functional domains (cervical spine function, upper extremity function, lower extremity function, bladder function and quality of life). The following criteria were calculated on the basis of the user's guide for the JOACMEQ: the subscale points, the transition of the median value (minimum value minus maximum value), and the effectiveness rate at each evaluation point after surgery. The JOA score and Hirabayashi recovery rate were also evaluated at each point. We measured the correlation between each JOACMEQ subscale and the JOA score at each point using Spearman contingency coefficients.

\section{Results}

Figs. 1 and 2 showed the average total JOA scores and av-

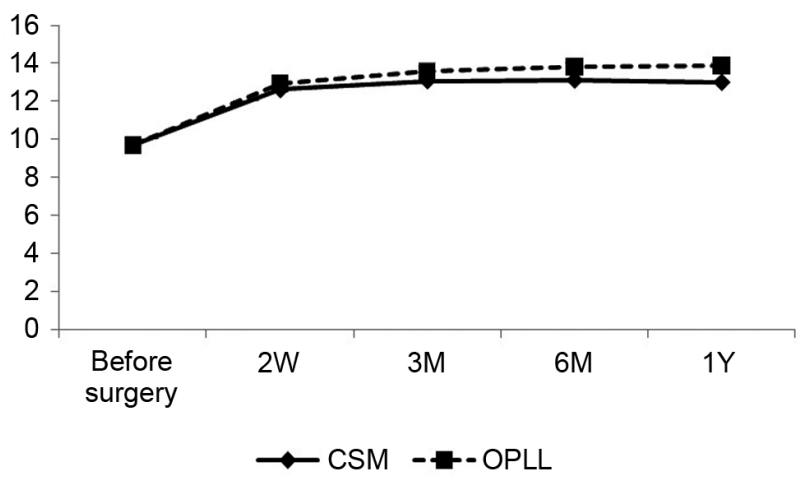

Fig. 1. Average total Japanese Orthopaedic Association scores for patients with cervical spondylotic myelopathy (CSM) and for those with ossification of the posterior longitudinal ligament (OPLL). M, months after surgery; $W$, weeks after surgery; $Y$, years after surgery.

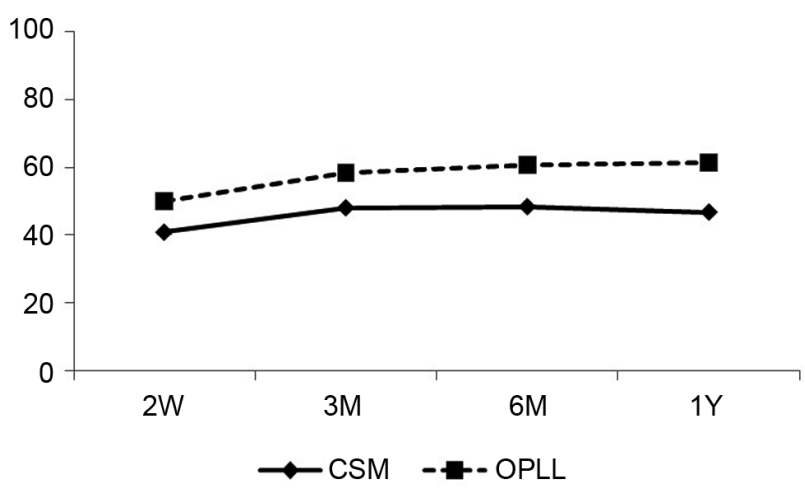

Fig. 2. Average Hirabayashi recovery rates (\%) for patients with cervical spondylotic myelopathy (CSM) and for those with ossification of the posterior longitudinal ligament (OPLL). $M$, months after surgery; $W$, weeks after surgery; $Y$, years after surgery. 
erage Hirabayashi recovery rates, respectively, at multiple time points. The 2 groups had similar results, but the recovery rates were slightly better in the OPLL group than in the CSM group. The average total JOA score and the recovery rate improved significantly after surgery in both groups $(p<0.01)$. The median score for each JOACMEQ subscale was shown in Figs. 3 and 4. When each subscale point was compared pre- and post-surgery in patients with CSM, the cervical spine function improved significantly at 3 months post-surgery and the function of upper and lower extremities improved significantly at every postoperative evaluation point. Scores for quality of life improved only at 2 weeks and 3 months after surgery (Fig. 3). The OPLL group showed no significant improvement

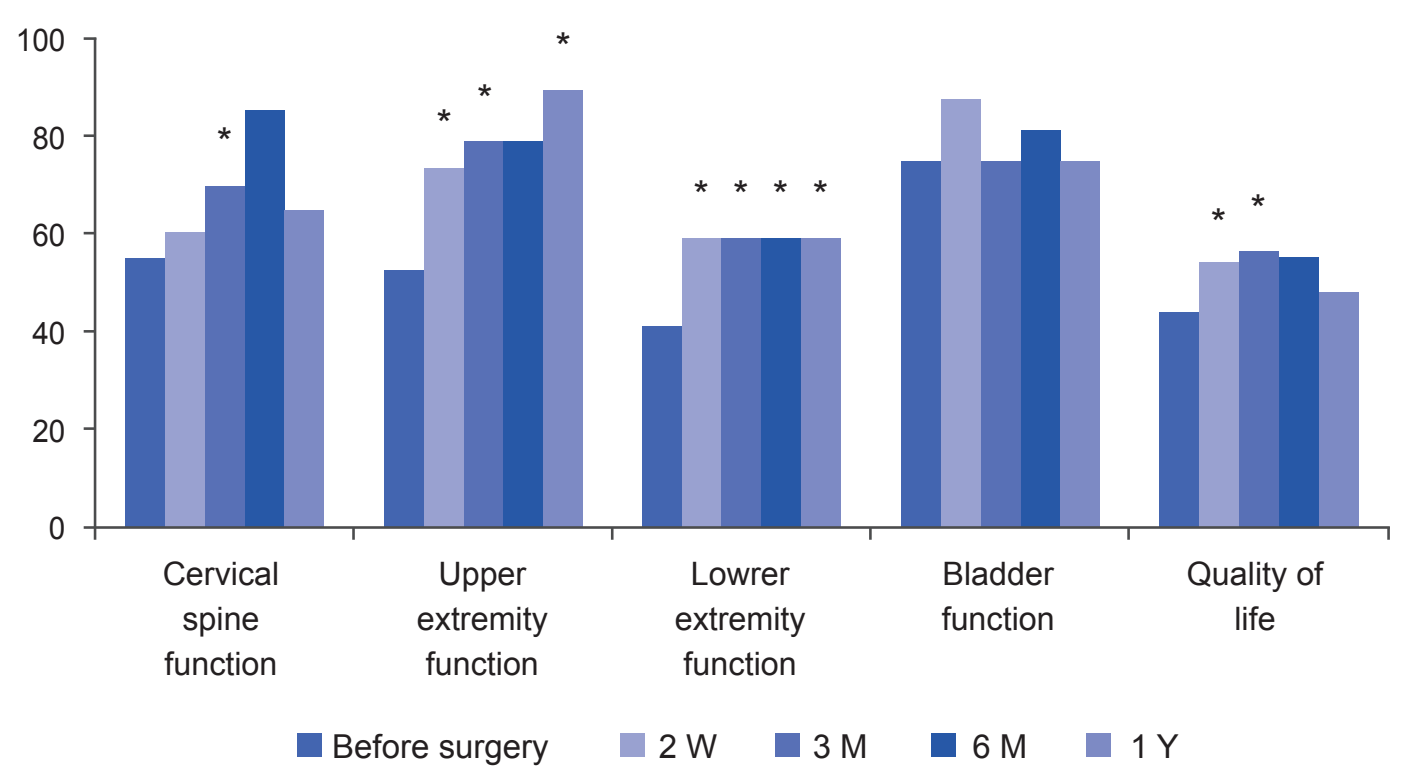

Fig. 3. The median for each Japanese Orthopaedic Association Cervical Myelopathy Evaluation Questionnaire subscale in the cervical spondylotic myelopathy group. $M$, months after surgery; W, weeks after surgery; $Y$, years after surgery. *Wilcoxon signed-rank test/Bonferroni method. $p<0.05 / 3$.

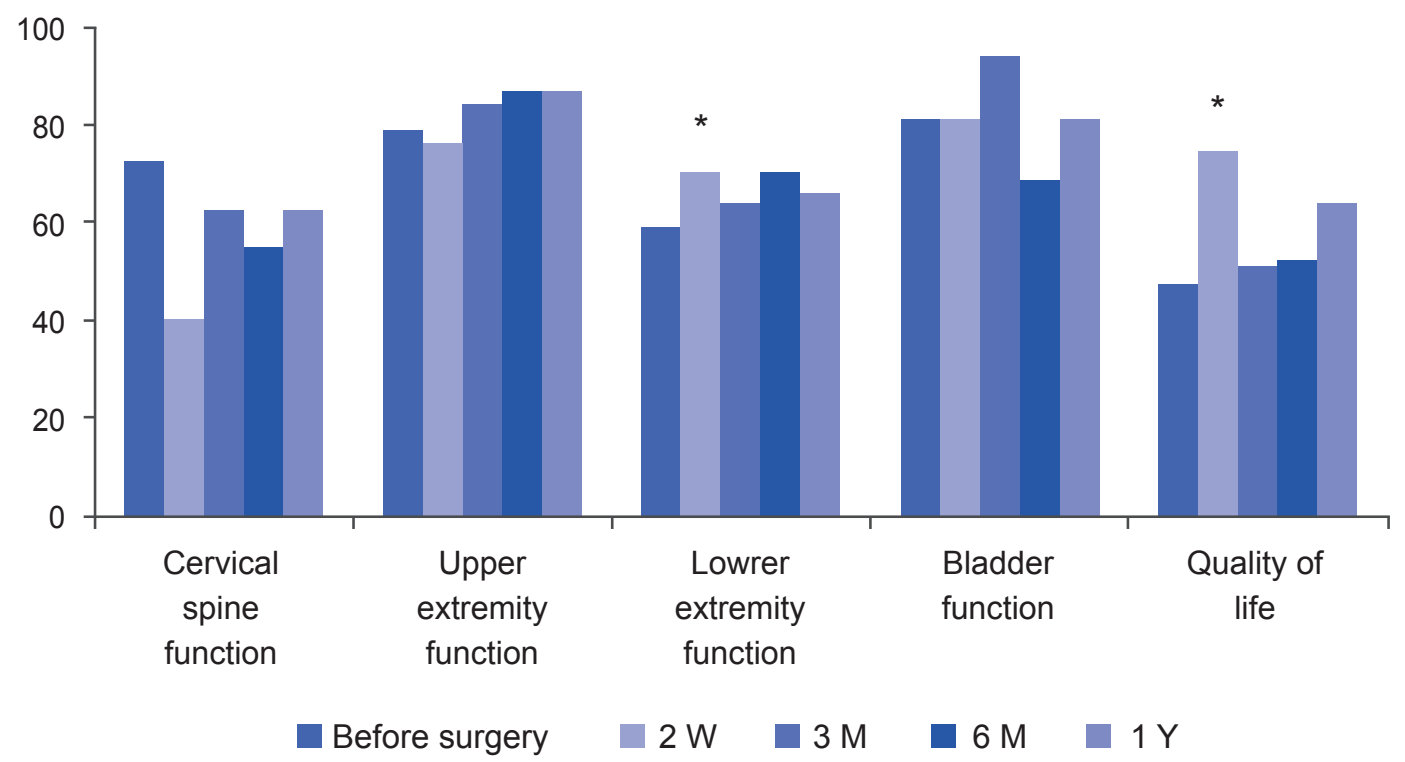

Fig. 4. The median for each Japanese Orthopaedic Association Cervical Myelopathy Evaluation Questionnaire subscale in the ossification of the posterior longitudinal ligament group. $M$, months after surgery; $W$, weeks after surgery; $Y$, years after surgery. *Wilcoxon signed-rank test/Bonferroni method. $p<0.05 / 3$. 
in the function of the cervical spine, upper extremities, or bladder. Lower-extremity function and quality of life improved significantly only at 2 weeks after surgery (Fig. 4). Figs. 5 and 6 showed the effectiveness rate for each JOACMEQ subscale in both groups. Table 1 showed the Spearman contingency correlation coefficients between each JOACMEQ subscale and the JOA score in both groups. The coefficients were widely dispersed in both groups, except for upper- and lower-extremity function.

\section{Discussion}

The current worldwide, standards for diagnosis of cervical spinal myelopathy are the Nurick scale [5] and the

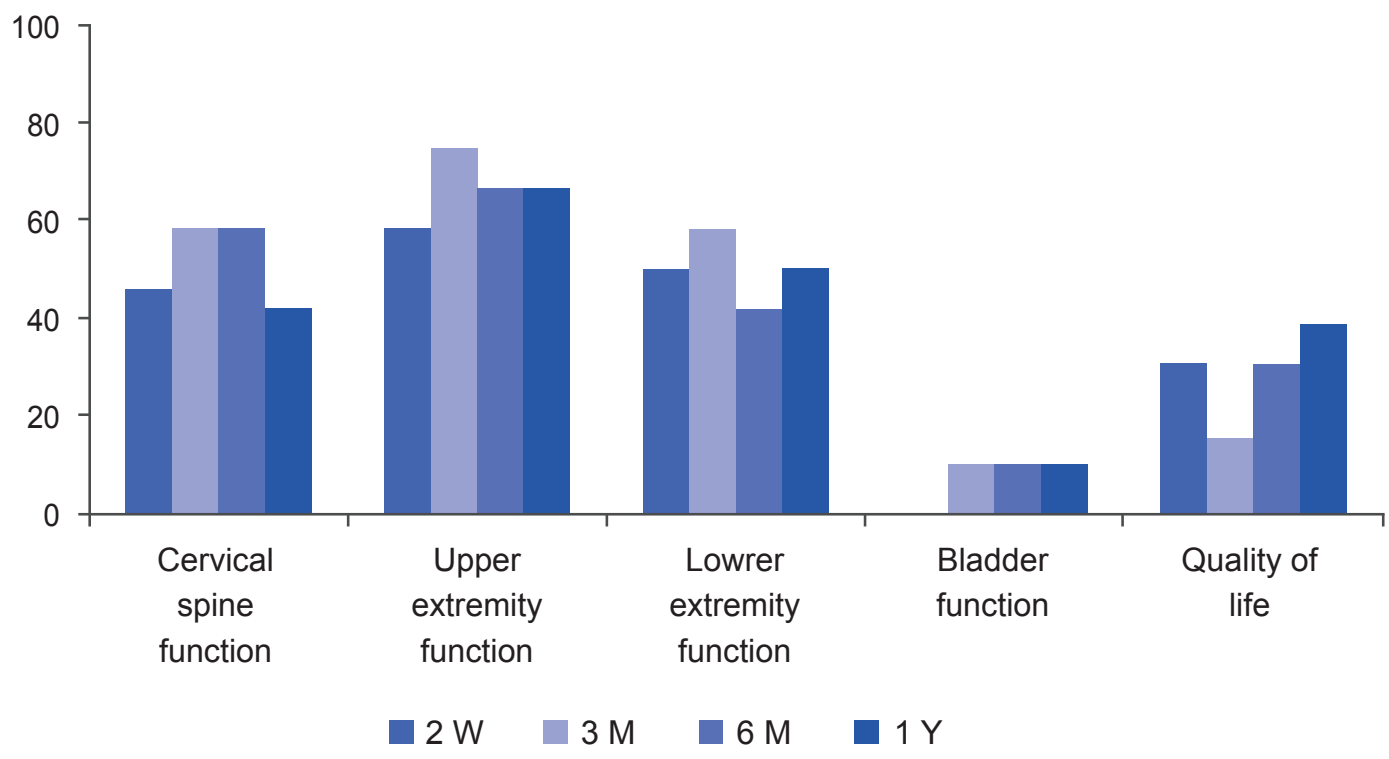

Fig. 5. The effectiveness rate (\%) for each Japanese Orthopaedic Association Cervical Myelopathy Evaluation Questionnaire subscale in the cervical spondylotic myelopathy group. $M$, months after surgery; $W$, weeks after surgery; $Y$, years after surgery.

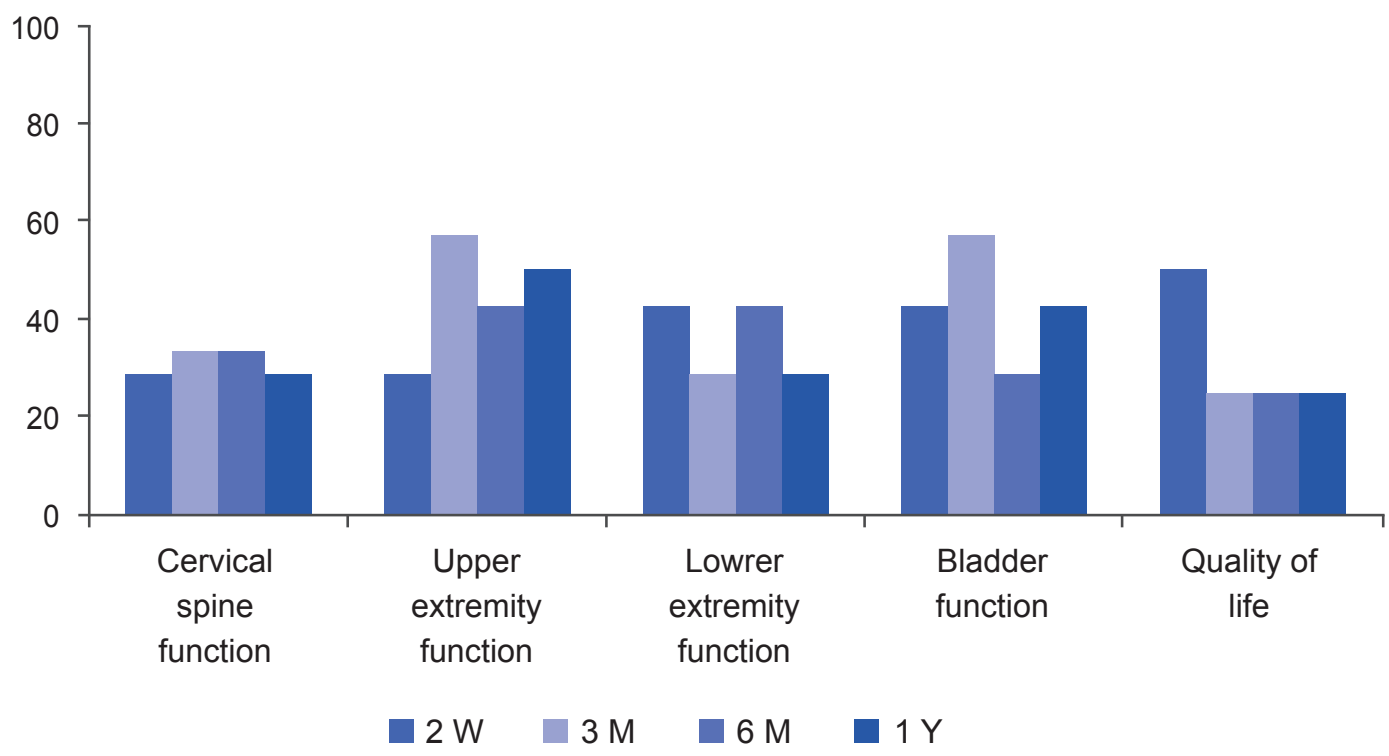

Fig. 6. The effectiveness rate (\%) for each Japanese Orthopaedic Association Cervical Myelopathy Evaluation Questionnaire subscale in the ossification of the posterior longitudinal ligament group. $M$, months after surgery; W, weeks after surgery; $Y$, years after surgery. 
Table 1. Correlation ${ }^{\text {a) }}$ between JOACMEO and JOA Scores

\begin{tabular}{|c|c|c|c|c|c|c|c|c|c|c|}
\hline \multirow[b]{2}{*}{ Characteristic } & \multicolumn{5}{|c|}{ CSM group } & \multicolumn{5}{|c|}{ OPLL group } \\
\hline & $\begin{array}{l}\text { Before } \\
\text { surgery }\end{array}$ & $2 W$ & $3 \mathrm{M}$ & $6 \mathrm{M}$ & $1 Y$ & $\begin{array}{l}\text { Before } \\
\text { surgery }\end{array}$ & $2 W$ & $3 \mathrm{M}$ & $6 \mathrm{M}$ & $1 Y$ \\
\hline Cervical spine function & 0.72 & 0.47 & 0.35 & 0.62 & 0.75 & 0.75 & 0.23 & 0.61 & 0.86 & 0.96 \\
\hline Upper extremity function & 0.75 & 0.32 & 0.47 & 0.50 & 0.81 & 0.81 & 0.86 & 0.90 & 0.86 & 0.91 \\
\hline Lower extremity function & 0.75 & 0.40 & 0.73 & 0.70 & 0.85 & 0.85 & 0.70 & 0.88 & 0.90 & 0.90 \\
\hline Bladder function & 0.27 & 0.44 & 0.56 & 0.72 & 0.73 & 0.46 & 0.68 & 0.62 & 0.91 & 0.79 \\
\hline Quality of life & 0.22 & 0.56 & 0.47 & 0.58 & 0.70 & 0.95 & 0.65 & 0.43 & 0.75 & 0.76 \\
\hline
\end{tabular}

JOACMEQ, Japanese Orthopaedic Association Cervical Myelopathy Evaluation Questionnaire; JOA, Japanese Orthopaedic Association; CSM, cervical spondylotic myelopathy; OPLL, ossification of the posterior longitudinal ligament; $W$, weeks after surgery; $M$, months after surgery; $Y$, years after surgery.

${ }^{\text {a) }}$ Calculated using Spearman contingency coefficients.

JOA score. Comparatively, the JOA score is the most useful, because the Nurick scale consists of only 6 simple grades. However, the JOA score is a physician-centered assessment tool created in 1975, which does not take into account patient satisfaction or quality of life. Both criteria are now considered important and are thus assessed by the JOACMEQ. Due to the emerging need to evaluate the impairments to patient activity in daily life, which is directly related to quality of life, various patient-oriented outcome measures, for example, the Short Form-36, have been developed and adopted by clinical practices in different medical fields. JOACMEQ was established to fulfill this need, as a self-rating questionnaire that could be filled out by patients themselves. Candidate questions included in the questionnaire were selected and modified from various preexisting outcome measures, including the Short Form-36, the Rolland and Morris Disability Questionnaire, and the Oswestry disability index. This questionnaire comprises 24 questions that were selected and validated through three large-scale studies. It designates the status of patients suffering cervical myelopathy from five different aspects, represented by five intuitive numerical scores. We found that the average JOA score was similar in both the CSM and OPLL groups. The transition of the average total JOA score before laminoplasty to that after laminoplasty have been documented elsewhere for patients with CSM and for those with OPLL:

- Seichi et al. [6] reported scores of 8.3 before surgery and 11.4 at 1 year after surgery for patients with CSM, and scores of 8.6 and 12.4, respectively, for patients with OPLL (2001).

- Suda et al. [7] reported scores of 9.9 before surgery and 14.0 at 2 years after surgery for patients with CSM (2003).

- Higashino et al. [8] reported scores of 9.4 before surgery and 12.7 immediately after surgery for patients with CSM (2006). At the latest follow-up examination, the mean JOA score was 12.0.

- Yukawa et al. [9] reported scores of 11.1 before surgery and 14.0 at 6 months after surgery for patients with CSM (2007).

- Iwasaki et al. [10] reported scores of 9.0 before surgery and 14.1 at 3 years after surgery for patients with OPLL (2002).

- Ogawa et al. [11] reported scores of 9.2 before surgery and 14.2 at 3 years after surgery for patients with OPLL (2004).

The recovery rates in the studies for patients with CSM were as follows: Suda et al. [7], 60.2\%; Higashino et al. [8], 43.4\%; Yukawa et al. [9], 60.6\%. The recovery rates for patients with OPLL were as follows: Iwasaki et al. [10], 63\%; Ogawa et al. [11], 63.1\%. The recovery rates in our study corroborated those from previous studies, with rates for the OPLL groups slightly better than rates for the CSM groups. However, we found that scores on the JOACMEQ subscale for cervical spine function improved gradually after surgery in the CSM group, while those in the OPLL group did not improve at all. The CSM group showed more improvement than the OPLL group in function of the upper and lower extremities, as assessed by the JOACMEQ. Generally, these results were already known from clinical experiments but could not be evaluated in detail using only conventional assessment. There was no significant improvement in bladder function at any point, 
as assessed by the JOACMEQ. Median scores for quality of life on the JOACMEQ improved significantly after surgery, but the rate for effectiveness of assessment was lower in both the CSM and the OPLL groups. Thus, reaching a consensus on the JOACMEQ effectiveness rate was difficult. For example, when looking at the upper- and lower-extremity function in the CSM group, we could judge that surgery was effective because the effectiveness rate was about $50 \%$ and the postoperative median score improved significantly compared with the preoperative score. Yet when looking at the quality of life, we could not determine whether surgery was effective, since the effectiveness rate was below $30 \%$, despite significant improvement of the postoperative median score as compared to the preoperative score. As shown in Table 1, there was no consistent correlation between each JOACMEQ subscale and the JOA score. Therefore, we concluded that since both evaluation methods were quite different they are both needed until more widespread consensus on the interpretation of the JOACMEQ becomes available. There was a general correlation between JOA scores and scores on the JOACMEQ subscale for upper- and lower-extremity function, reflected by a lack of large distance between scores on the physician-centered tool (JOA) and those on the patient-centered tool (JOACMEQ). However, in the OPLL group, we found no obvious correlation between scores on the 2 assessment tools for either cervical spine function or quality of life; and in the CSM group, the correlation was low between scores on the 2 tools for cervical spine function. The new subscales of cervical spine function and quality of life were parameters that we could not assess with the JOA score. Most previous studies that assessed cervical spine function by evaluating the range of motion, degree of spinal curvature, or axial pain, did not provide adequate assessment with a patient-centered method. Agrawal et al. [12] recently reported assessment of quality of life using Odom's criteria. Chagas et al. [13] assessed quality of life with a 3 -grade scale, Singh et al. [14] did so by the Short Form-36, and Kotani et al. [15] used the JOACMEQ subscale for quality of life. Despite all these prior assessments, no researcher had measured time-dependent postoperative changes affecting quality of life for patients with CSM or with OPLL. The salient feature of our study was the use of the JOACMEQ to assess cervical spine function and quality of life, parameters that cannot be assessed by the JOA scores. The JOACMEQ includes items assessed by the JOA score, but the
JOACMEQ and the JOA score produce different findings because there is no consistent correlation between each JOACMEQ subscale and the JOA score. Hence both assessments should continue to be used until there is more consensual interpretation of the JOACMEQ. Our study had several limitations. Firstly, only 8 of the study subjects had OPLL. Secondly, the follow-up period was only 1 year. Thirdly, we could not easily implement our findings on the JOACMEQ because there was little consensus regarding the correspondence of its effectiveness rate to practical clinical relevance. The JOA score significantly corresponded to scores for the JOACMEQ subscales for upper- and lower-extremity function. However, for the OPLL group, the JOA score did not correlate with the JOACMEQ subscales for cervical spine function and quality of life. Moreover, in the CSM group, scores on the JOACMEQ cervical spine function subscale had little relation to JOA scores. These results indicated that the JOA score alone was not useful in assessing cervical spine function or quality of life.

\section{Conclusions}

We reported time-dependent postoperative changes in the JOACMEQ and JOA scores in patients with CSM or OPLL who underwent cervical laminoplasty. Scores on subscales of the JOACMEQ for upper- and lower-extremity function correlated with JOA scores. The JOACMEQ can assess cervical spine function and quality of life, factors that cannot be assessed by the JOA score alone, hence the JOACMEQ is a more comprehensive modality of evaluation.

\section{Conflict of Interest}

No potential conflict of interest relevant to this article was reported.

\section{Acknowledgments}

Medical editor Katharine O'Moore-Klopf, ELS (East Setauket, NY, USA) provided professional English-language editing of this article.

\section{References}

1. Fukui M, Chiba K, Kawakami M, et al. An outcome 
measure for patients with cervical myelopathy: Japanese Orthopaedic Association Cervical Myelopathy Evaluation Questionnaire (JOACMEQ): Part 1. J Orthop Sci 2007;12:227-40.

2. Fukui M, Chiba K, Kawakami M, et al. Japanese Orthopaedic Association Cervical Myelopathy Evaluation Questionnaire (JOACMEQ): Part 2. Endorsement of the alternative item. J Orthop Sci 2007;12:241-8.

3. Fukui M, Chiba K, Kawakami M, et al. Japanese Orthopaedic Association Cervical Myelopathy Evaluation Questionnaire (JOACMEQ): part 4. Establishment of equations for severity scores. Subcommittee on low back pain and cervical myelopathy, evaluation of the clinical outcome committee of the Japanese Orthopaedic Association. J Orthop Sci 2008;13:2531.

4. Fukui M, Chiba K, Kawakami M, et al. JOA Back Pain Evaluation Questionnaire (JOABPEQ)/JOA Cervical Myelopathy Evaluation Questionnaire (JOACMEQ). The report on the development of revised versions. April 16, 2007. The Subcommittee of the Clinical Outcome Committee of the Japanese Orthopaedic Association on Low Back Pain and Cervical Myelopathy Evaluation. J Orthop Sci 2009;14:34865.

5. Nurick S. The natural history and the results of surgical treatment of the spinal cord disorder associated with cervical spondylosis. Brain 1972;95:101-8.

6. Seichi A, Takeshita K, Ohishi I, et al. Long-term results of double-door laminoplasty for cervical stenotic myelopathy. Spine (Phila Pa 1976) 2001;26:47987.

7. Suda K, Abumi K, Ito M, Shono Y, Kaneda K, Fujiya $\mathrm{M}$. Local kyphosis reduces surgical outcomes of expansive open-door laminoplasty for cervical spondylotic myelopathy. Spine (Phila Pa 1976) 2003;28:125862.
8. Higashino K, Katoh S, Sairyo K, Sakai T, Kosaka H, Yasui N. Preservation of C7 spinous process does not influence the long-term outcome after laminoplasty for cervical spondylotic myelopathy. Int Orthop 2006;30:362-5.

9. Yukawa Y, Kato F, Ito K, et al. Laminoplasty and skip laminectomy for cervical compressive myelopathy: range of motion, postoperative neck pain, and surgical outcomes in a randomized prospective study. Spine (Phila Pa 1976) 2007;32:1980-5.

10. Iwasaki M, Kawaguchi Y, Kimura T, Yonenobu K. Long-term results of expansive laminoplasty for ossification of the posterior longitudinal ligament of the cervical spine: more than 10 years follow up. J Neurosurg 2002;96:180-9.

11. Ogawa Y, Toyama Y, Chiba K, et al. Long-term results of expansive open-door laminoplasty for ossification of the posterior longitudinal ligament of the cervical spine. J Neurosurg Spine 2004;1:168-74.

12. Agrawal D, Sharma BS, Gupta A, Mehta VS. Efficacy and results of expansive laminoplasty in patients with severe cervical myelopathy due to cervical canal stenosis. Neurol India 2004;52:54-8.

13. Chagas H, Domingues F, Aversa A, Vidal Fonseca AL, de Souza JM. Cervical spondylotic myelopathy: 10 years of prospective outcome analysis of anterior decompression and fusion. Surg Neurol 2005;64 Suppl 1:S30-5.

14. Singh A, Gnanalingham K, Casey A, Crockard A. Quality of life assessment using the Short Form-12 (SF-12) questionnaire in patients with cervical spondylotic myelopathy: comparison with SF-36. Spine (Phila Pa 1976) 2006;31:639-43.

15. Kotani Y, Abumi K, Ito M, et al. Minimum 2-year outcome of cervical laminoplasty with deep extensor muscle-preserving approach: impact on cervical spine function and quality of life. Eur Spine J 2009;18:663-71. 